Fifth International Conference on Sustainable Construction Materials and

Technologies. http://www.claisse.info/Proceedings.htm

\title{
Tyres an Environmentally Sustainable Resource?
}

\author{
Tedge Sagoo ${ }^{1, a}$, Noel W Peart ${ }^{1}$, Chris Sawden ${ }^{1}$
}

${ }^{1, a}$ The End Journey Ltd. UK. <londondivision@ @outlook.com>

\begin{abstract}
Having a significant interest in waste disposal, I focused on the significant issues relating to the disposal of "waste" tyres. During my research I read papers produced by Mike Winter and JD Simms, who are both leading researchers in the field of the use of PAS 108 tyre bale, which is suitable for civil engineering projects. This together with other case studies have shown tyre bales are a valuable resource suitable for many different civil engineering projects, such as drainage in earthworks, in sea defences and bank protection.

Other research undertaken by Ganjian et al., (2009) ${ }^{(1)}$, looked into mixing rubber crumb into concrete - used in the State of California. This method could reduce cost, thereby offering an effective solution for the utilities industry, in the maintenance of services. Moreover, he confirmed that studies into rubber crumb derived from recycled tyres should be considered as non-hazardous waste. This report investigates Civil Engineering application and methodologies of using tyre bales, as a sustainable construction material with the add benefits reducing the carbon foot print of any given highway project by reducing the direct and indirect $\mathrm{CO} 2$ emissions generated or trade-offs, such a potential risk of fire.
\end{abstract}

Keywords: Tyres, Sustainability, Environment

\section{Introduction}

This report sets out the concept of sustainable development, highlights the significant issues arising from the disposal of redundant tyres, before turning to consider the use of tyres in a positive manner, reflects on experiences and concludes that waste tyres should be viewed in a positive light rather than as a problem.

\section{Sustainable Development}

Today sustainability underpins the whole Town Planning process with its foundations traced back to the World's First Earth Summit in Rio in 1992. The original definition of sustainable development is usually considered to be:

"Development that meets the needs of the present without compromising the ability of future generations to meet their own needs." (Butland Report for the World Commission on Environment and Development 1992) (2) 


\section{Tyre Disposal}

The UK Tyre Recovery Association (TRA), represents the UK's tyre recovery sector, which processes over 40 million used tyres every year, and estimate that 500,000 tonnes of rubber tyres enter the waste stream across the UK each year. This in itself raises a significant challenge because tyres are among the most difficult items to recycle given that they're made up of a combination of steel, rubber and textile.

In 2006, the EU Landfill Directive no longer permits end-of-life tyres at landfill sites, which means all tyres must be recycled or re-used in some way, shape or form.

The government are currently working towards zero landfill and landfill expected to be full by 2025. Creating an issue as to what to do with all these tyres generated by road users an estimated 60 million plus per year.

There are limited opportunities for disposal:

- to ship abroad. It Is unethical and irresponsible to let someone else clear up after us and benefit from our missed opportunity;

- To burn in cement kilns as tyre derived fuel for the manufacture of new material, which in itself creates a ton of carbon for every ton of cement manufactured.

- Utilise this asset to reduce carbon and turn to a speedier way of building; each layer of sub grade requires compaction, which in return is labour intense and time consuming.

- Alternatively excavate lower bale back fill cap with top coat reducing compaction by $100 \%$, material by $75 \%$, estimated time saving of job $40 \%$, reducing lorry movements of material to site by $75 \%$, improving air quality by $100 \%$ by using this carbon neutral aggregate.

Historically the disposal of tyres has been a headache for all involved in the industry. This is illustrated by a man being jailed for 15 months in November 2011 for illegally dumping more than one million tyres across England. It was reported that this case was:

"Significantly bigger than the last major conviction for tyre dumping. In 2009, 175,000 tyres and 290 tonnes of tyre wire were dumped by three people across 
England and Wales.", (3)

The Head of Waste and Illegals at the Environment Agency at the time commented:

"Huge tyre dumps are not only an eyesore, but also present a serious risk to the environment and human health. Stockpiles are a significant fire risk, as they can burn for several years, releasing dangerous gases such as hydrogen sulphide, hydrogen cyanide and sulphur dioxide." (3)

\section{Proactive Tyre Use - Road Construction}

The construction industry is required to create sustainable solutions, in order to reduce the carbon footprint, to meet the balance between environmental and economic needs. In order to meet its emissions goals, the EU transport sector must reduce greenhouse gas emissions by at least $60 \%$ by 2050 , compared to 1990 levels.

Currently, total greenhouse gas emissions for UK road infrastructure stand at 2782 kilo tonnes of $\mathrm{CO} 2$ equivalents per year ${ }^{(4)}$. In 2009 sections of the A421 were built with recycled tyre bales, debunking the myth that road building has to be carbon intensive. The A421 is a key part of the east-west corridor and an essential link between Cambridge and Oxford. It is largely single carriageway between the M1 and Bedford, and this stretch is used by more than 25,000 vehicles a day, resulting in significant congestion and associated environmental harm.

Traditionally roads are constructed with four different types of material namely, stone gravel, sand and asphalt. The substitution of tyre bale - in road construction - for the natural resources of stone, gravel and sand, results in significant environmental benefits. It primarily reduces the need to source natural materials and the associated environmental damage, whilst disposing of waste tyres in an environmentally friendly way, reducing the need to export overseas. In summary - an all-round sustainable approach.

The A421 project team has used the resources of transport research body TRL Director Mike Winter, who pioneered the use of tyres on Scottish road projects. The success of the tyre bale fill, centres on keeping its long-term settlement to a minimum and this has been proven by tests from these projects, which showed that only $1.1 \%$ of creep was recorded over a 35-month period. (5) Further research was also carried out by BRE to guarantee that the tyre bale foundations would not be flammable. The bales have a 50-year design life and the project team is confident that the foundations will not require any more maintenance than a conventional road, so much so that it has offered Bedfordshire County Council a warranty on the design. 
Dr Mike Winters research suggests the best way when working with bales is to lay the bale in a flotation method, rather than just bury the material into the ground, advising to compact the bale in with clay.

\section{$\underline{\text { Specification and Manufacture of Tyre Bales }}$}

The table below summarises the size, density, permeability and other technical characteristics of bales used in the construction project described in this case study, and details the number and weight of the tyres.

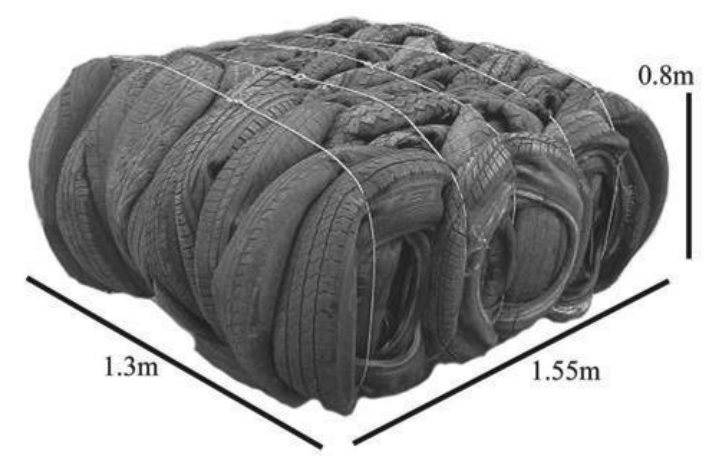

- Size of bale 1.5 X 1.2 X $0.8 \mathrm{~m}$

- $\quad$ Bulk volume of bale $1.26 \mathrm{m3}$

- Weight of bale $0.75-0.8$ tonnes

- Bulk density of bale $0.64 \mathrm{t} / \mathrm{m} 3$

- Approximate number of tyres per bale 100 - 110 tyres

- Permeability (bale) $0.14-0.04 \mathrm{~m} / \mathrm{sec}$

- $\quad$ Aggregate equivalence $300 \mathrm{~mm}$

- Binder strand material Galvanised high

- tensile strength wire

\section{Golf Course Access Track}

In 2017, via my network, contact was made from a golf club in Kent, experiencing maintenance and usability issues and associated access difficulties, to their course during winter months, as there was no buggy track. This resulted in an instruction to investigate inter alia, design work for possible service roads and cart tracks, factoring in environmental issues. 
A series of "borehole tests" was undertaken, it was found that the existing ground conditions, illustrated a very low California Bearing Ratio (CBR). In light of these findings, it was considered that traditional road construction methods would not be appropriate given the ground conditions. Moreover, there was a foreseeable risk of creating long term maintenance problem.

For these reasons, an alternative solution was sought, which resulted in the recommendation of the use of tyre bale and its utilisation in the formation of the road sub-base level. This came with its obvious advantages creating a porous solution to the identified problem, providing the golf club with its essential access, whilst at the same time producing a cost-effective solution to the issue.

The cart track design was heavily informed by Kent County Council's "Road Pavement Design Guide."

This advises that the requirement for a sub base is $150 \mathrm{~mm}$, with capping layers ranging $450 \mathrm{~mm}$ $-600 \mathrm{~mm}$.

The dimensions of a tyre bale are approximately $1.55 \mathrm{~m}$ wide, $1.3 \mathrm{~m}$ deep and $0.8 \mathrm{~m}$ high and are a perfect fit for the standard requirements of new road construction.

The use of PAS 108 bale material is accepted by the Environment Agency and therefore has the backing of the Government. To date projects have been trailed using this method of alternate material but do not appear to have made it into the main stream of road construction. Bales can also be and are used in drainage applications, especially in landfill to prevent leaching; these have been approved by the BSI and developed by WRAP alongside HR Wallingford.

\section{Other Benefits}

These include:

- Sustainability

- A solution to the current need to export waste tyres

- Advantages of construction speed against traditional aggregate

- Strengthen comparison of bale v aggregate

- Reduction of lorry movements with an increase in air quality 
- Reduction on the need to extract natural resources and a subsequent increase in environmental conditions that would be otherwise local to the source

- Incentives

- Government and planning policies

- Rubber technology and science

- Environmental enhancements

In addition it is a more cost-effective solution, with a 2019 quote ${ }^{(6)}$ for materials cost for subbase based per tonne, and based on delivery on a $28 \mathrm{t}$ artic, with the caveat that prices are quoted subject to availability:

- Primary $10 \mathrm{~mm}$ shingle $£ 22.00$ per $\mathrm{t}$

- Primary $20 \mathrm{~mm}$ shingle $£ 21.00$ per $\mathrm{t}$

- $0 / 20 \mathrm{~mm}$ ballast $\quad £ 21.00$ per $\mathrm{t}$

- Reject sand $\quad £ 13.00$ per $\mathrm{t}$

- Primary mot type $1 \quad £ 22.25$ per $\mathrm{t}$

- Sharp washed sand $£ 21.00$ per $\mathrm{t}$

- Building sand $\quad £ 18.75$ per $\mathrm{t}$

\section{Conclusion}

Road users require tyres, roads require material, tyres require disposal "end of life." It raises a simple query, if you need tyres to use a road, then why not make the roads out of old tyres. The disposal of waste tyres, need not be a monumental problem as it is currently perceived and could in reality prove a cost effective, environmentally friendly, sustainable solution and friend to the construction and infrastructure industry. The use of tyre bales in construction and development is a win-win situation, commonly described in 2019 as a "no brainer."

\section{References}

1. Ganjian, E, Khorami, M and Maghsoudi, A, "Scrap-tyre rubber replacement for aggregate and filler in concrete", Construction and Building Materials, Vol. 23, No. 5, pp 1828-1836, (ISSN 0950-0618), DOI:10.1016/j.conbuildmat.2008.09.020, May 2009.

2. The Global Learning - Global Footprints

3. The Guardian 8 November 2011

4. https://www.adb.org/sites/default/files/publication/28555/estimating-carbon-footprintsroad-projects.pdf.

5. Winter M.G.Transport Research Laboratory (TRL), Edinburgh, United Kingdom.

6. Gavin Fleary, Lords Builders Merchants 